\section{WHO FCTC article 5.3: promise but little progress}

\author{
Ruth E Malone, Stella Aguinaga Bialous
}

Six years after the Third Session of the Conference of the Parties to the WHO Framework Convention on Tobacco Control (FCTC) adopted strong implementation guidelines for the treaty's Article 5.3, ${ }^{1}$ that article's promise for protecting tobacco control policymaking from tobacco industry interference remains almost entirely unrealised. While some government agencies, mostly healthfocused, have instituted policies about contact with industry representatives, no government has fully publicised and implemented policies throughout government to insulate the policymaking process from tobacco company shenanigans. In fact, in some cases governments seem to be moving backward as they develop new 'partnerships' with tobacco companies around illicit trade issues, particularly during negotiations for and adoption in November 2012 of the WHO FCTC Protocol to Eliminate Illicit Trade in Tobacco Products. The protocol has specific language about respecting implementation of Article 5.3 and explicitly cautions that obligations under the protocol should not be performed by or delegated to the tobacco industry. ${ }^{2}$

For examples of backward-facing initiatives, in Azerbaijan, Japan Tobacco International organised a seminar for the States Customs Committee to discuss progress in addressing cigarette smuggling. ${ }^{3}$ In Mali, BAT and Imperial tobacco companies are jointly supporting an awareness campaign on illicit trade with the National Directorate of Trade \& Competition ${ }^{4}$; in Namibia, the Ministry of Finance signed a Memorandum of Understanding with the Tobacco Institute of South Africa to collaborate in combating illicit trade. ${ }^{5} 6$ In the Caribbean, British American Tobacco hosted an event to discuss contraband for Customs and other government agencies. ${ }^{7}$

These partnerships not only breach the intent and the letter of Article 5.3, they create additional complexity for tobacco

Department of Social and Behavioral Sciences, School of Nursing, University of California, San Francisco, San Francisco, California, USA

Correspondence to Professor Ruth E Malone, Department of Social and Behavioral Sciences, School of Nursing, University of California, San Francisco, San Francisco, California 94118, USA; ruth.malone@ucsf.edu control efforts as government personnel develop 'partner' relationships with tobacco industry employees. While illicit tobacco trade is a significant issue for governments, research has shown that major multinational tobacco companies have themselves been involved in tobacco smuggling. ${ }^{8-11}$ The illicit trade issue is also used as a threat in order to keep cash-strapped governments from enacting stronger tobacco control policy measures. Research has demonstrated that tobacco companies are funding surveys of questionable methodological quality which inevitably show large increases in illicit trade associated with tobacco control that are inconsistent with independent surveys. $^{12} 13$

The tobacco companies are also using international trade treaties to bully national governments and threaten their sovereignty over their own public health policies, increasingly in the implementation of packaging and labelling policies (Article 11 of the WHO FCTC). Philip Morris International sued Uruguay over its large graphic pack warnings and restrictions on brand variants under a bilateral trade and investment treaty; the company has also sued Australia, Norway and Ireland over attempts to institute plain packaging and retail display bans. The tobacco industry has also sued Nepal and Thailand, and it lost in Sri Lanka but it is appealing the Court's decision. Tobacco companies are aggressively using the threat of infringement of trade agreements as a deterrent or negotiating point, which may have a chilling effect on tobacco control implementation or at a minimum, as in Namibia, Jamaica, Solomon Islands and Sri Lanka, result in a weakening or nonenforcement of policies (eg, decrease in the size of warning labels, lack of implementation). ${ }^{14}$

To date, few trade agreement infringement arguments have been successful in international courts (pending several cases); but it is important to remember that while issues of trade and trade agreements are important for many countries, as with illicit trade, Parties to the FCTC do not have carte blanche to simply ignore the treaty and its Article 5.3. Trade departments may think they are 'exempt' from Article 5.3, and that mistaken belief provides an enormous opening for the industry to undermine public health through working laterally. In fact, ALL government departments of countries that are Parties to the FCTC, including those that negotiate trade treaties, are subject to the provisions of Article 5.3. They can have discussions with the industry, as long as these follow a set of rules of interaction, and above all, are fully transparent so that the longstanding patterns of secrecy favouring the industry are not perpetuated.

In one example of a government providing clear guidance to overseas embassies and posts regarding Article 5.3, the UK bars 'activities with the specific purpose of promoting the sale of tobacco or tobacco related products; encouraging investment in the tobacco industry; attending or otherwise supporting receptions or high profile events, especially those where a tobacco company is the sole or main sponsor and/or which are overtly to promote tobacco products or the tobacco industry; endorsing or recommending any tobacco company; endorsing projects which are funded directly or indirectly by the tobacco industry; etc. ${ }^{15}$ This may be the first such guidance not developed primarily via the health sector of a government, and it is significant in light of stories of embassies protecting the interests of the multinationals against domestic policy in host countries, or ignoring the public health implications of industry policy involvements. For example, in a reported recent visit by the Turkish ambassador to Jordan to the Philip Morris International Jordan headquarters, the company shared with the ambassador its 'proactive' strategy on illicit trade, which was to reduce tobacco prices! ${ }^{16}$

Other countries that are taking Article 5.3 at least somewhat seriously include New Zealand, which has a strong code of conduct that is government wide; Finland, which has severe restrictions on government representatives meeting with industry, and the Philippines, which has developed ethical guides on tobacco industry interaction that apply to all government sectors, although it is unclear how well implemented these have been. ${ }^{17}$ However, in all cases, the issue is whether well-intentioned policies are aggressively promulgated and enforced.

Full implementation of the FCTC is a role of all government agencies-it is not optional for some and required for others. Every time a department, agency, or any government representative engages in any activity that breaches Article 5.3, it risks setting back progress on all the other provisions of the Treaty. The first 
recommendation of the guidelines for implementing Article 5.3 calls for governments to 'raise awareness' about the role of the tobacco industry, and part of effective implementation of its provisions should be sharing widely with the public how the industry's insidious activities require government to institute special provisions in order to protect the public. Governments that have stopped prioritising the tobacco industry's interests over those of their own citizens deserve praise and support from the global community. Dirty ashtrays to those governments that continue to facilitate the spread of the tobacco epidemic by not ending the corrupting influence of the industry.

Contributors Both the Authors have equal contributions.

Competing interests None.

Provenance and peer review Not commissioned; internally peer reviewed.

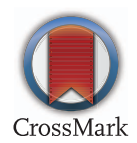

To cite Malone RE, Bialous SA. Tob Control 2014;23:279-280.

Accepted 30 May 2014

Tob Control 2014;23:279-280.

doi:10.1136/tobaccocontrol-2014-051817

\section{REFERENCES}

1 World Health Organization. WHO Framework Convention on Tobacco Control Guidelines for Implementation of Article 5.3. 2008. http:// wwwwhoint/fctc/guidelines/article_5_3pdf

2 World Health Organization Conference of the Parties. Protocol to eliminate illicit trade in tobacco products. https://treatiesunorg/Pages/DBaspx?path=DB/Opening\% 20for\%20Signature/page1_enxml\&menu=MTDSG. 2012.

3 Aliyev E. Tobacco smuggling decreased in Azerbaijan. Trend Newsagency http://entrendaz/capital/business/ 2243667html, 2014.

4 Imperial Tobacco Group. Combating illicit trade in Mali. 2014. http://www.noodls.com/view/6CE06 F02D07888A586AE66F35A38B715DCA7349F? $9543 \times x \times 1397640978$

5 Sasman C. Noose to tighten on contraband cigarettes. Namibian. January 9 2013. http://www. namibian.com.na/indexx.php?archive_id=103974\& page_type=archive_story_detail\&page $=484$

6 Staff. A huff and a puff save money. Namibia Economist. 2014. http://www.economist.com.na/ markets/2619-a-huff-and-a-puff-save-money

7 Staff. BahamalslandsInfo. Bahamas Customs learns to detect illicit tobacco trade activities. 11 July 2013. http://www.bahamaislandsinfo.com/index.php? option=com_content\&view=article\&id=15218: bahamas-customs-learns-to-detect-illicit-tobaccotrade-activities-\&catid=34:Bahamas $\% 20$ National $\%$ 20News\&Itemid = 147

8 Collin J, Legresley E, MacKenzie R, et al. Complicity in contraband: British American Tobacco and cigarette smuggling in Asia. Tobacco Control 2004;13(Suppl 2):104-11.

9 Guevara MW. The world's most widely smuggled legal substance. International Consortium of Investigative Journalists. 2008. http://wwwicijorg/ project/tobacco-underground/worlds-most-widelysmuggled-legal-substance

10 Woodhall C. The tobacco industry's role in smuggling needs scrutiny. Cancer Research UK. 2013. http:// scienceblogcancerresearchukorg/2013/06/13/thetobacco-industrys-role-in-smuggling-needs-scrutiny/

11 European Parliament News. Cigarette smuggling: Experts urge MEPs to confront tobacco industry. 2014. http://wwweuroparleuropaeu/news/en/newsroom/content/20140127ST033904/html/Cigarettesmuggling-experts-urge-MEPs-to-confront-tobacco-industry

12 Rowell G, Evans-Reeves K, Gilmore AB. Tobacco industry manipulation of data on and press coverage of the illicit tobacco trade in the UK. Tobacco Control 2014;23(e1):e35-43.

13 Gilmore AB, Rowell A, Gallus $S$, et al. Towards a greater understanding of the illicit tobacco trade in Europe: a review of the PMI funded 'Project Star' report. Tobacco Control 2014;23(e1):e51-61.

14 Tavernise S. Tobacco Firms' Strategy Limits Poorer Nations' Smoking Laws. New York Times 13 December 2013. http://wwwnytimescom/2013/12/ 13/health/tobacco-industry-tactics-limit-poorernations-smoking-lawshtml? pagewanted $=$ all\&_r $=0$

15 World Health Organization. United Kingdom of Great Britain and Northern Ireland-guidance for embassies on interactions with the tobacco industry published. March 2014. http://wwwwhoint/fctc/ implementation/news/news_uk14/en/

16 AME Info. Philip Morris International/Jordan receives Turkish Ambassador at its headquarters. 2014. http://wwwameinfocom/blog/finance/philip-morrisinternational-jordan-receives-turkish-ambassadorheadquarters/

17 Republic of the Philippines. Joint memorandum circular no. 2010-01. 2010. http://wwwtobaccocontrollawsorg/ files/live/Philippines/Philippines\%20-\%20JMC\% 202010-01\%20-\%20nationalpdf 